\title{
Green synthesis and characterization of zinc oxide nanoparticles using bashful (Mimosa pudica), leaf extract: a precursor for organic electronics applications
}

\author{
Sunday Wilson Balogun ${ }^{1} \cdot$ Olusola Oladele James $^{2} \cdot$ Yekini Kolawole Sanusi $^{3} \cdot$ Oyeshola Hakeem Olayinka ${ }^{3}$
}

Received: 19 August 2019 / Accepted: 29 January 2020 / Published online: 28 February 2020

(c) Springer Nature Switzerland AG 2020

\begin{abstract}
Efforts has been intensified in the field of research for nanomaterials to bridge the gap for energy supply in this century. A plant- based material that may provide solutions to the current energy crisis may be found in nanomaterials. Green synthesis of nanoparticles using plant extract is gaining importance as an alternative to conventional chemical and physical method of synthesis, because of its simplicity and environmental friendliness. In this research we synthesized Zinc oxide nanoparticle (ZnO.NPs) using plant extracts and deposited using spin- coating technique. The obtained samples were characterized by UltraViolet-Visible spectrophotometer, Fourier Transform Infra-Red spectroscopy (FTIR), Scanning Electron Microscopy (SEM), X-Ray Diffraction (XRD) and Solar simulator for electrical properties. The maximum absorption peaks occurred at $235 \mathrm{~nm}, 250 \mathrm{~nm}, 270 \mathrm{~nm}$, and $300 \mathrm{~nm}$ respectively but lower when compared with the bulk size that occurred at $350 \mathrm{~nm}$ and in the visible spectrum of the wavelength band. Band gap energy of zinc oxide nanoparticle at $500 \mathrm{rpm}$ was $3.50 \mathrm{eV}$. ZnO.NPs FTIR spectrum was recorded in the range of $4000-500 \mathrm{~cm}^{-1}$. The synthesis $\mathrm{ZnO} \mathrm{NPs}$ FTIR result shows $\mathrm{Zn}-\mathrm{O}$ functional group was found at low wavenumber. SEM images of the samples give information on the morphology which are spherical and granular nature. The XRD pattern of synthesized nanoparticles shows that the substances only belong to $\mathrm{ZnO}$ since there is no diffraction peaks of other impurities and the average grain size of the particles was estimated to be $14.7 \mathrm{~nm}$. ZnO.NPs thin film device under illumination has efficiency of $0.7 \%$. Based on electrical properties of the fabricated thin film device, the parameter shows it could be suitable for photoanode of Dye sensitized solar cell.
\end{abstract}

Keywords ZnO Nanoparticles · Optical properties · Synthesis · Characterization · Visible spectrum · Plant extract

\section{Introduction}

Challenges in energy sector coupled with quest for ecofriendly and environment friendly source of energy has called for more research in solar energy. The branch of technology that studies different materials at a nanometric scale is referred to as nanotechnology and it is also defined as science of production, manipulation and use of materials at subatomic level that finds its application in materials science, engineering, and electronics. A plantbased material that may provide solutions to the current energy crises may be found in Nanomaterials. Synthesis of nanoparticles using plant extract is gaining importance as an alternative to conventional method of synthesis because of its simplicity and environmental friendliness. $\mathrm{ZnO}$ is an inorganic material with high electron mobility

Sunday Wilson Balogun, sbalogun94@gmail.com; Olusola Oladele James, Olusola.james@kwasu.edu.ng; Yekini Kolawole Sanusi, sanusiyk33@gmail.com; Oyeshola Hakeem Olayinka, hoyeshola@pgschool.lautech.edu.ng| ${ }^{1}$ Department of Materials Science and Engineering Laboratory, Kwara State University Malete, Ilorin, Nigeria. ${ }^{2}$ Department of Pure and Applied Chemistry, Kwara State University Malete, Ilorin, Nigeria. ${ }^{3}$ Department of Pure and Applied Physics, Ladoke Akintola University of Technology, Ogbomoso, Nigeria. 
and easy to prepare as electron acceptor to dissociate excitons formed in conjugated polymer as the active material of solar cells. The objectives of this research are to understand the synthesis of zinc oxide nanoparticles using plant extract (bashful leaves) whose sustainable potential is inherent in its availability in abundance in our environment, to explore the behavior of zinc oxide nanoparticles thin films in certain condition and characterize ZnO.NPs thin film as a precursor for organic electronics applications. The research focus on synthesis, characterization of ZnO.NPs and evaluation of its properties. Zinc oxide ( $\mathrm{ZnO})$ is an inorganic material that has found its uses in many applications and can be prepared as a nanoparticle [1-9]. Zinc oxide nanoparticles (ZnONPs) has been widely used as donor material due to its superior optoelectronic properties and its relatively easy to be synthesized by using the following methods: ultrasound, anodization, co-precipitation, sol-gel method, chemical vapor deposition and mechanochemical-thermal synthesis. [10] in their research reported that the synthesized $\mathrm{ZnO}$ nanoparticles are moderately stable, roughly spherical with maximum particles in size range within 9-10 $\mathrm{nm}$ in diameter. [11] reported the synthesis of $\mathrm{ZnO}$ nanoparticles using Trifolium pratense flower extract characterized using different methods to study the efficacy of the synthesized $\mathrm{ZnO}$ nanoparticles against clinical and standard strain. [12] in their article Green medicated synthesis and characterization of $\mathrm{ZnO}$ nanoparticles using Euphorbia Jatropa latex as reducing agent reported that latex plant played an important role in controlling the size of the particle and its morphology. [13] reported that Mimosa pudica and coffee powder extracts materials have crystallite size of around $27.14 \AA$ and $46.94 \AA$ and that Photocatalytic activity of $\mathrm{ZnO}$ nanoparticles is related to the crystallite size as well as band gap energy values. [14] reported that $\mathrm{ZnO}$ nanoparticles have a good electrochemical activity and are consider as a potential electrocatalyst. Zinc oxide nanoparticles (ZnO-NP) has been widely developed as donor material due to its superior optoelectronic properties and its relatively easy to be synthesized by using solution methods. [15] used a sol-gel method to synthesis and study ZnO NPs. [16] carried out green synthesis of nanoparticles by biological systems they reported peaks absorption around $350 \mathrm{~nm}$ due to large excitation binding energy at room temperature. $\mathrm{ZnO}$ nanoparticles was blended with a poly-3-hexyl-thiophene as active material for high performance solar cell by [17, 18] blended $\mathrm{ZnO}$.NPs with P3HT and an improvement was reported in interchains and intrachains ordering when compared to pure P3HT. Power conversion efficiency of solar cells also improved. ZnO.NPs was characterized by means of UV-Vis spectroscopy for optical properties, Scanning Electron Microscopy (SEM) for morphology, chemical structure by means of Fourier Transform Infra-Red (FTIR) spectroscopy, X-Ray Diffraction (XRD) for ZnONPs pattern and Solar Simulator to determine its electrical properties.

\section{Experimental}

\subsection{Materials}

The materials used were bashful leaves ( $M$. pudica), Zinc acetate dihydrate, Ethanol, Sodium hydroxide $(\mathrm{NaOH})$. Beakers glass, petri dish, filter papers, oven, spatula, and magnetic stirrer were some of the instruments used to carry out the research work.

\subsection{Methodology}

All experimental procedures of preparation of the thin films was performed under ambient air. The glove-box facility was not available for the research.

\subsubsection{Substrate preparation}

Clean rectangular glass slides of dimension $25.4 \mathrm{~mm}$ by $76.2 \mathrm{~mm}$ were used as substrates. The glass substrates were washed with detergent solution for 10-15 $\mathrm{min}$ in ultrasonic sonicator and rinsed in distilled water for $15 \mathrm{~min}$ at $30^{\circ} \mathrm{C}$. The substrate was cleaned with Isopropanol alcohol (IPA) in ultrasonic bath for $15 \mathrm{~min}$ at $30^{\circ} \mathrm{C}$ and dried in a stream of nitrogen gas $\left(\mathrm{N}_{2}\right)$.

\subsubsection{Preparation of plant extract}

$30 \mathrm{~g}$ of Ewe patanmon (Yoruba name), bashful leaves ( $M$. pudica), were collected and washed thoroughly with distilled water to remove dirt and the residual moisture. The leaves were grinded into powder after drying in ambient temperature, $0.4 \mathrm{~g}$ of the powder sample was added into $40 \mathrm{ml}$ of ethanol solvent and stirred for $24 \mathrm{~h}$ without heat using magnetic stirrer. The solution was filtered. The extract was stored and kept away from ray of the sun.

\subsubsection{Preparation of aqueous zinc acetate dihydrate solution}

$0.168 \mathrm{~g}$ of Zinc acetate dehydrate was dissolved in $20 \mathrm{ml}$ of ethanol at room temperature. The solution was heated at $90^{\circ} \mathrm{C}$ for 40 min using magnetic stirrer. The solution was left to cool under ambient temperature.

\subsubsection{Synthesis of zinc-oxide nanoparticles (ZnO.NPs)}

$0.5 \mathrm{M}$ aqueous solution of zinc acetate dihydrate prepared was added to $10 \mathrm{ml}$ of plant extract which was stirred 
without heat for $4 \mathrm{~h}$ using magnetic stirrer for homogenous mixture. Sodium hydroxide $(\mathrm{NaOH})$ solution was then prepared by mixing it with ' $0.8 \mathrm{M}$ aqueous ethanol and stirred without heat for $4 \mathrm{~h}$. The two solutions were added together and stirred for $6 \mathrm{~h}$ for homogenous mixture and chemical reaction. $\mathrm{Zn}(\mathrm{OH})_{2}$ precipitate that settled at the bottom of the sealed beaker was obtained by removal of excess mother liquor. The precipitate $\mathrm{Zn}(\mathrm{OH})_{2}$ by-products was removed by washing with deionized water and acetone. Heating process or baking was carried out at the temperature of $300^{\circ} \mathrm{C}$ for $45 \mathrm{~min}$ to evaporate the solvent in a carbolite tubular furnance (Srw 21-501042 Type-CT17) and to convert $\mathrm{Zn}(\mathrm{OH})_{2}$ into zinc-oxide nanoparticles (ZnO.NPs) particle powder.

\subsubsection{Deposition of synthesized zinc-oxide nanoparticles (ZnO.NPs)}

ZnO.NPs solution was prepared and deposited on glass substrate at different spin-coating speed using spin -coater (laurel WS-650 Hz-23NPP). Spin coating speeds of $3000 \mathrm{rev}-$ olution per minute (rpm), $2000 \mathrm{rpm}, 1500 \mathrm{rpm}, 1000 \mathrm{rpm}$, $750 \mathrm{rpm}$, and $500 \mathrm{rpm}$ were considered respectively for $30 \mathrm{~s}$ corresponding to thin film layer thicknesses of $32 \mathrm{~nm}, 35 \mathrm{~nm}$, $87 \mathrm{~nm}, 115 \mathrm{~nm}, 146 \mathrm{~nm}$, and $177 \mathrm{~nm}$ respectively. Depending on the speed of rotation (rpm) of the spin coater, the desirable thickness of the sample was obtained. It is important to note that the thickness of film being spin-coated depend on both time and speed of rotating stub as specified by equipment manufacturer in absence of surface profilometer.

\subsubsection{Zinc oxide nanoparticles characterization}

ZnONPs characterization was performed with UV-Vis spectrophotometer (Avantes Avalight-DH-5-BAL), Fourier transform infra-red spectroscopy (BUK, Infrared spectrophotometer model M530), Scanning Electron Microscope (SEM), X-Ray Diffractor (XRD), and Solar Simulator equipped with Keithley2400 SMU for current-voltage measurement. UV-VIS spectrophotometer (Avantes Avalight-DH-5-BAL) was used to record the transmittance and reflectance in percentage (\%). Absorbance was calculated using Eq. (1).

$\mathrm{A}=2-\log (\% \mathrm{~T}) \mathrm{a} u$

where $\mathrm{A}$ is the absorbance, \%T is the percentage transmittance.

Band gap energy of ZnO.NPs was calculated using Eq. (2) $[19,20]$.

$(\alpha h \nu)^{1 / n}=A(h \nu-E g)$ or $(\alpha h \nu)^{2}=h \nu-E g$

where (hv) is the photon energy the values were determined from the inverse relationship between energy in electron volts (eV) and wavelength of the UV-visible spectrum using Eq. (3).

$E=h c / q \lambda(e V)$

$\mathrm{E}=$ Photon energy, $\mathrm{h}=$ planck's constant $\left(6.626 \times 10^{-34}\right.$ J s), C = speed of light $\left(3.0 \times 10^{8}\right), \lambda=$ wavelength in nanometres $(\mathrm{nm}), \mathrm{q}=$ electronic charge $\left(1.6 \times 10^{-19} \mathrm{C}\right)$, $\left.1 \mathrm{eV}=1.6 \times 10^{-19} \mathrm{C}\right), \mathrm{a}=$ absorption coefficient, $\mathrm{Eg}=$ optical band gap, $A=$ constant and $n=1$ or 4 . The energy band gap was obtained from straight line plot of $(a h v)^{2}$ versus hu by extrapolating of the line to base line. The absorption coefficient (a) of thin film was calculated using Eq. (4) [21].

$\alpha=2.303(\mathrm{~A} / \mathrm{t})$

\subsection{7 $\mathrm{ZnO}$ nanoparticle thin film device fabrication}

To fabricate ZnONPs thin film device. ZnONPs solution was deposited by spin-coating method on Indium tin oxide (ITO) coated glass substrate as counter electrode, and thickness of film depended on the number of rpm $(117 \mathrm{~nm})$. Silver paste was deposited as the electrode. $\mathrm{ZnO}$ film thin film were heated at $100^{\circ} \mathrm{C}$ in an oven for $30 \mathrm{~min}$ to evaporate solvent.

\subsubsection{I-V characteristics measurement}

The current- voltage characterization of thin film device fabricated was carried out under illumination of solar Simulator with Kiethley 2400 SMU. Short-circuit current $\left(I_{S C}\right)$ and open-circuit voltage $\left(\mathrm{V}_{\mathrm{OC}}\right)$ were measured and noted. Fill factor (FF) and efficiency of the solar cell were calculated. Current-Voltage (I-V) measurements was performed to determine ZnONPs electrical properties.

\section{Results and discussion}

\subsection{UV-Vis spectra analysis of zinc oxide nanoparticles}

Figure 1 shows the transmittance of ZnO.NPs deposited at different spin-coating speed. The solution at $500 \mathrm{rpm}$ among the deposition at different spin coating speed has the highest absorption value and least transmittance after optical properties characterization in the visible spectrum of wavelength band (400-900 nm) as shown in Fig. 2. It can be seen in Figs. 3 and 4 that the absorption spectrum of the ZnO.NPs at $500 \mathrm{rpm}$ lies at 235-300 nm in UV spectrum of wavelength band in agreement as reported by [22]. The maximum absorption peaks occurred at $235 \mathrm{~nm}$, $250 \mathrm{~nm}, 270 \mathrm{~nm}$, and $300 \mathrm{~nm}$ respectively but lower when 


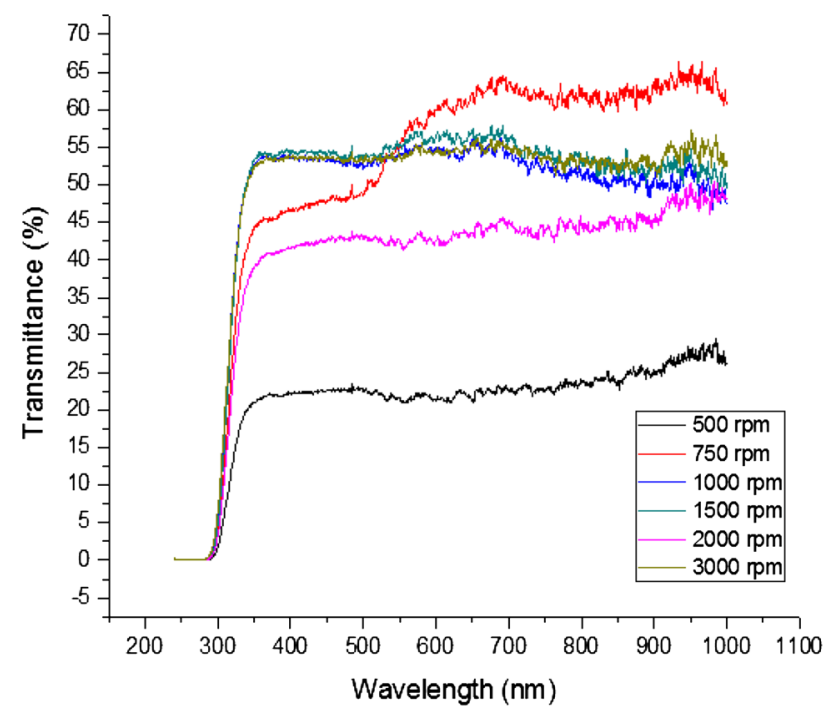

Fig. 1 Transmittance versus wavelength graph of ZnO.NPs at different spin-coating speed

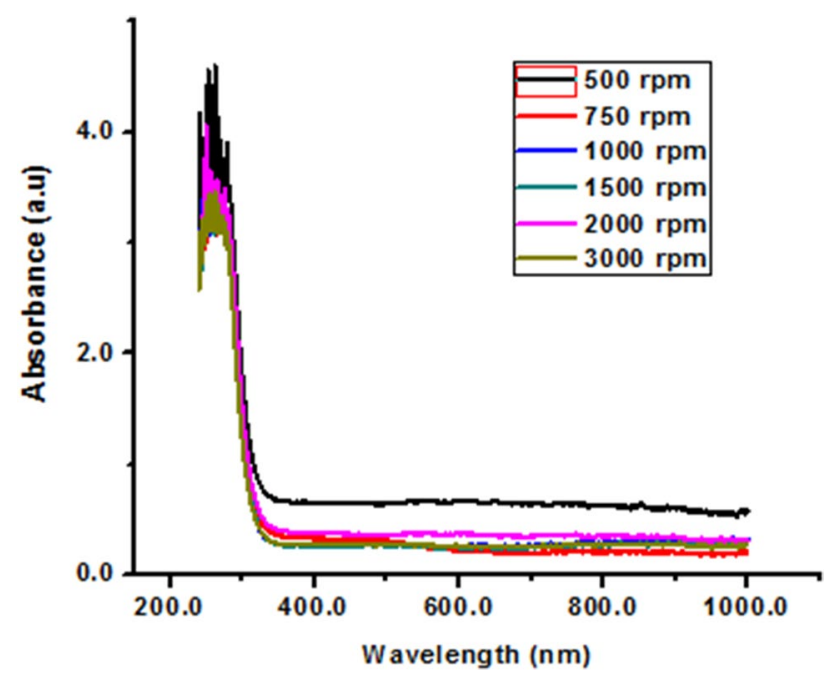

Fig. 2 Absorbance versus wavelength graph of ZnO.NPs at different spin-coating speed

compared with the bulk size that occurred at $350 \mathrm{~nm}$ and in the visible spectrum of the wavelength band. Figure 5 shows band gap energy graph of zinc oxide nanoparticle at $500 \mathrm{rpm}$, the obtained band gap energy was $3.50 \mathrm{eV}$ which is agreement with research study reported by [23, 24]. This shows thickness of plant extract and ZnO.NPs composites has effect on photon energy absorption.

Fourier transform infra-red spectroscopy analysis of Zinc Oxide Nanoparticle FTIR reveals the chemical structure of a material using vibrational states to recognize the presence of specific bonds. FTIR (BUK, Infrared spectrophotometer model M530) was used

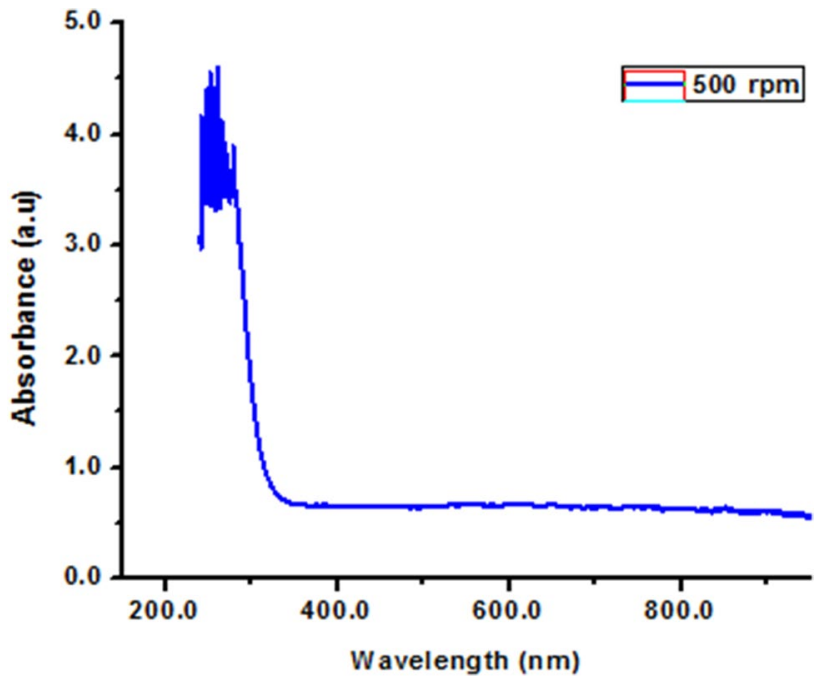

Fig. 3 Absorbance versus wavelength graph of ZnO.NPs

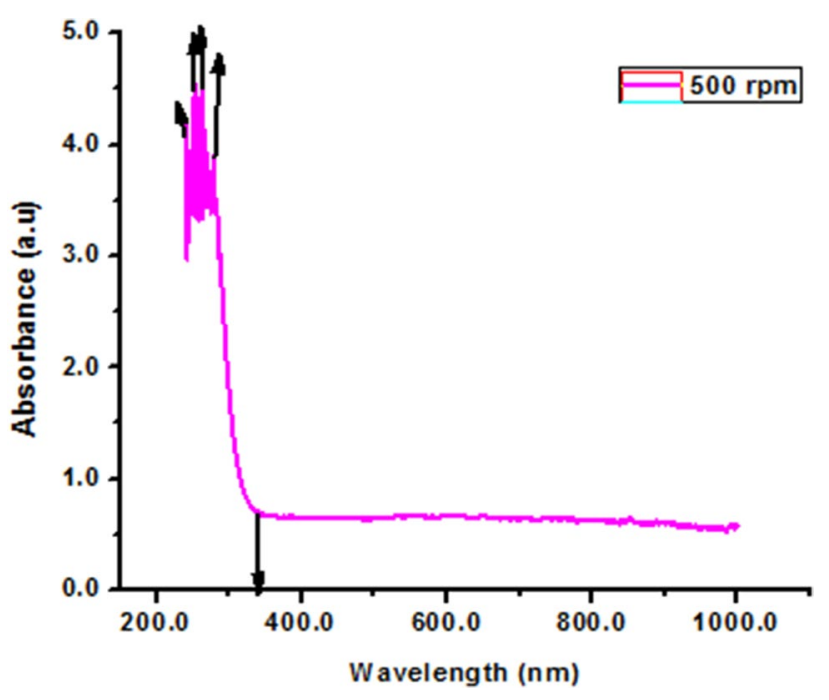

Fig. 4 Absorbance versus wavelength graph of ZnO.NPs

for IR characterization. FTIR spectrum of ZnO.NPs was obtained from sample deposited at $500 \mathrm{rpm}$ corresponding to $117 \mathrm{~nm}$ thickness. Figure 6 shows the IR spectrum of the sample of ZnO.NPs at deposited on glass substrate at $500 \mathrm{rpm}$. ZnO.NPs FTIR spectrum was recorded in the range of $4000-500 \mathrm{~cm}^{-1}$, observation shows that the bands of ZnO.NPs occurs at $3903.4 \mathrm{~cm}^{-1}, 3626.4 \mathrm{~cm}^{-1}$, $2802.2 \mathrm{~cm}^{-1}, 2395.4 \mathrm{~cm}^{-1}, 2195.9 \mathrm{~cm}^{-1}, 1963.2 \mathrm{~cm}^{-1}$, $1905.0 \mathrm{~cm}^{-1}, 1834.5 \mathrm{~cm}^{-1}, 1643.0 \mathrm{~cm}^{-1}, 1494.9 \mathrm{~cm}^{-1}$, $1288.7 \mathrm{~cm}^{-1}, 1194.7 \mathrm{~cm}^{-1}, 969.8 \mathrm{~cm}^{-1}, 882.6 \mathrm{~cm}^{-1}$, $783.4 \mathrm{~cm}^{-1}$ and $682.6 \mathrm{~cm}^{-1}$. The FTIR result of synthesized nanoparticles shows $\mathrm{Zn}-\mathrm{O}$ functional group are was found at low wavenumber as shown in Figs. 6 and 7 which agreed with results reported by $[7,11,15,24$, 25] (Table 1). 


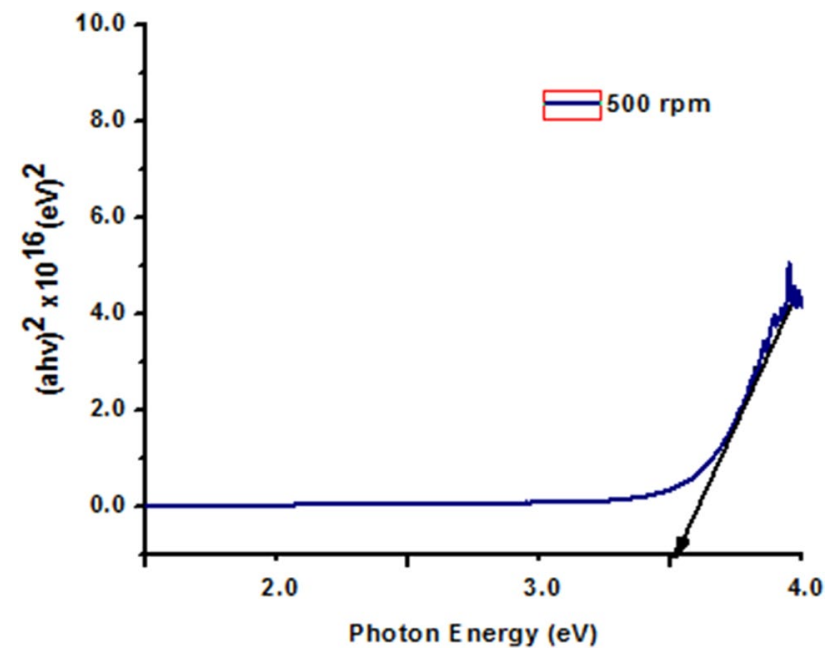

Fig. 5 Tauc plot of $(a h v)^{2}$ versus (hv) for band gap energy

\subsection{Scanning electron microscope image of zinc oxide nanoparticles}

The Fig. $8 \mathrm{a}$, b gives the typical SEM images of the sample at $300 \mu \mathrm{m}$ and $100 \mu \mathrm{m}$ respectively. The images give information on the morphology of the sample prone to aggregation due to the surface area to volume ratio which are spherical and granular nature for both resolutions. The larger particle size of the nanostructure was observed which gave bigger

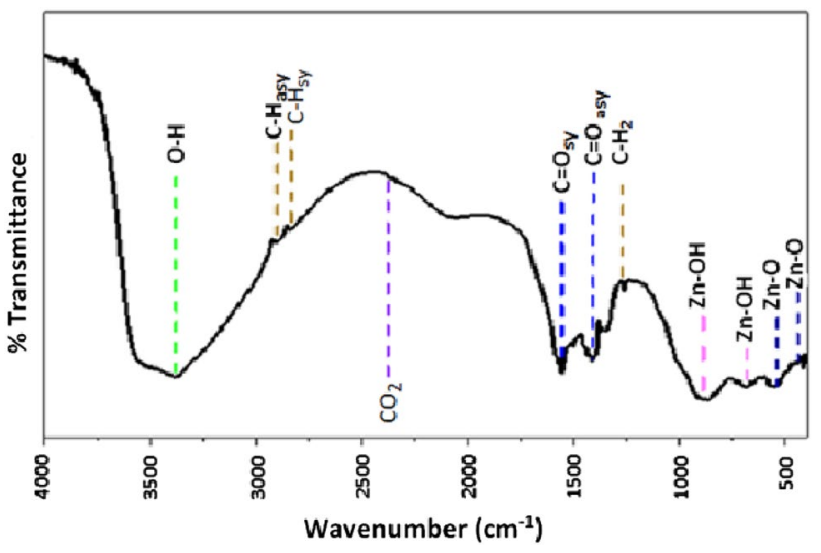

Fig. 7 FTIR spectrum of zinc oxide nanoparticles [15]

surface for the dye attached and thus more light can be absorbed and harvested. In addition, this structure of $\mathrm{ZnO}$ provides direct pathways for the electrons to move through the cell and thus increase the energy conversion rate.

\subsection{X-ray diffraction pattern of zinc oxide nanoparticles}

The XRD pattern of powder ZnO.NPs was shown in Fig. 9. All the peaks of the XRD patterns are indexed to $\mathrm{ZnO}$ with the hexagonal wurtzite structure. In comparison with the

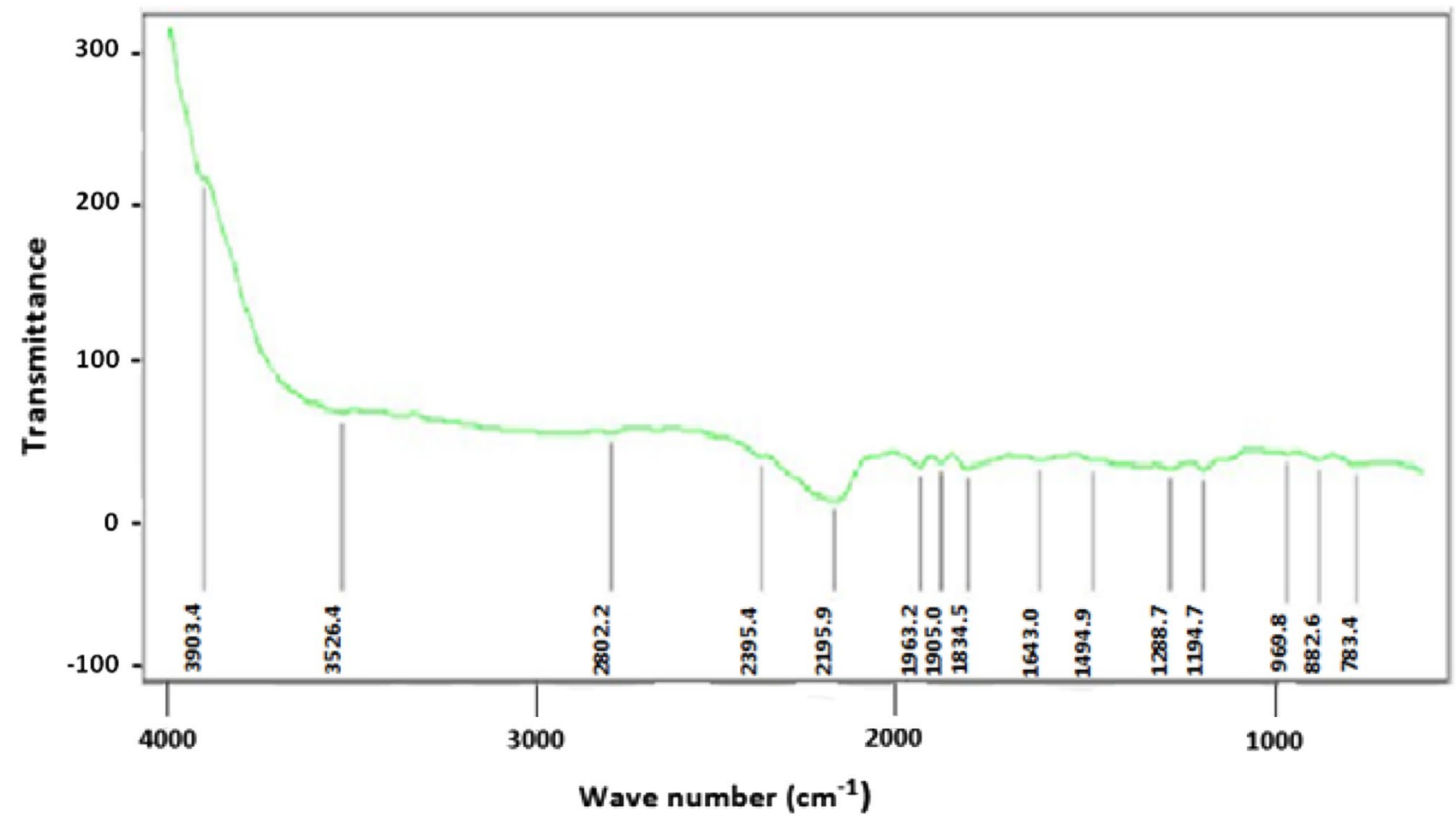

Fig. 6 Synthesized ZnO NPs FTIR spectra at 500 rpm Using Mimosa pudica Extract 
Table 1 Functional groups of synthesized ZnO.NPs Using Mimosa pudica Extract

\begin{tabular}{|c|c|c|}
\hline Wave number $\left(\mathrm{cm}^{-1}\right)$ data obtained & Functional group & $\begin{array}{l}\text { Wavenumber } \\
\left(\mathrm{cm}^{-1}\right)^{\prime \prime} \text { Refer- } \\
\text { ences" }\end{array}$ \\
\hline $1494.9,1288.7,1194.7969 .8,882.6,783.3682 .6$ & $\mathrm{Zn}-\mathrm{OH}, \mathrm{Zn}-\mathrm{O}$. Variety of single bond & {$[15,26-29]$} \\
\hline $1963.2,1854.5,1905.0,1643.0$ & $\mathrm{C}=\mathrm{O}, \mathrm{C}=\mathrm{N}, \mathrm{C}=\mathrm{C}$. absorption caused by double bonds & \\
\hline $2395.4,2195.9$ & Absorption caused by triple bond & \\
\hline $3903.4,3626.4,2802.2$ & $\mathrm{~N}-\mathrm{H}, \mathrm{C}-\mathrm{H}$ and $\mathrm{O}-\mathrm{H}$ absorption caused by single bond & {$[15,30,31]$} \\
\hline
\end{tabular}

Fig. 8 a SEM Image of ( $\mathrm{ZnO}$. NPs) at $300 \mu \mathrm{m}$ b SEM Image of (ZnO.NPs) at $100 \mu \mathrm{m}$
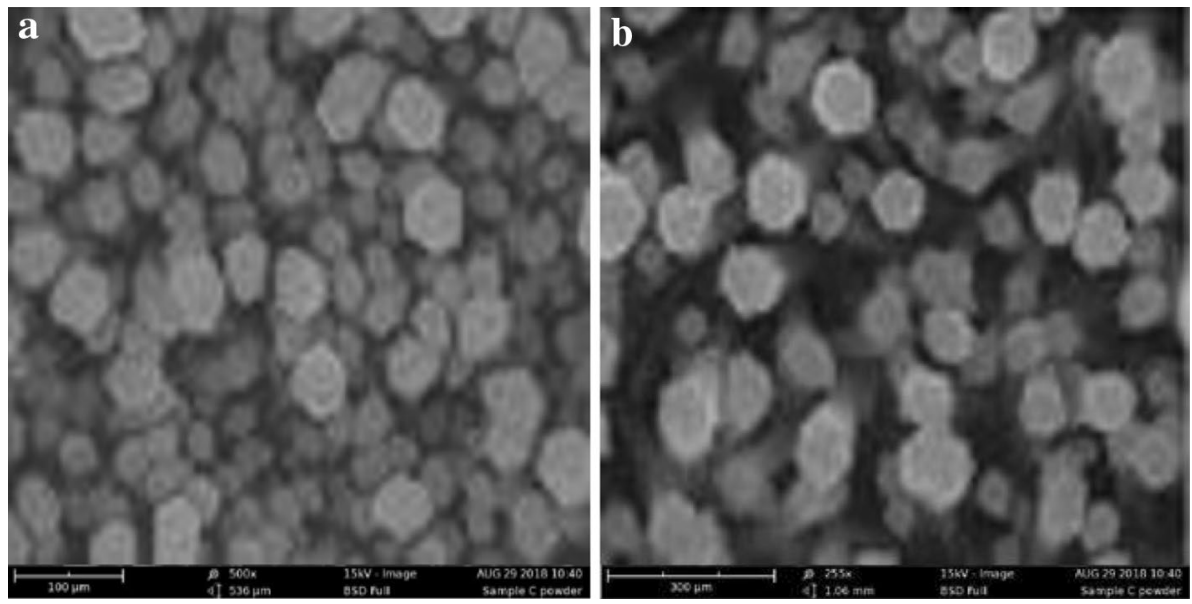

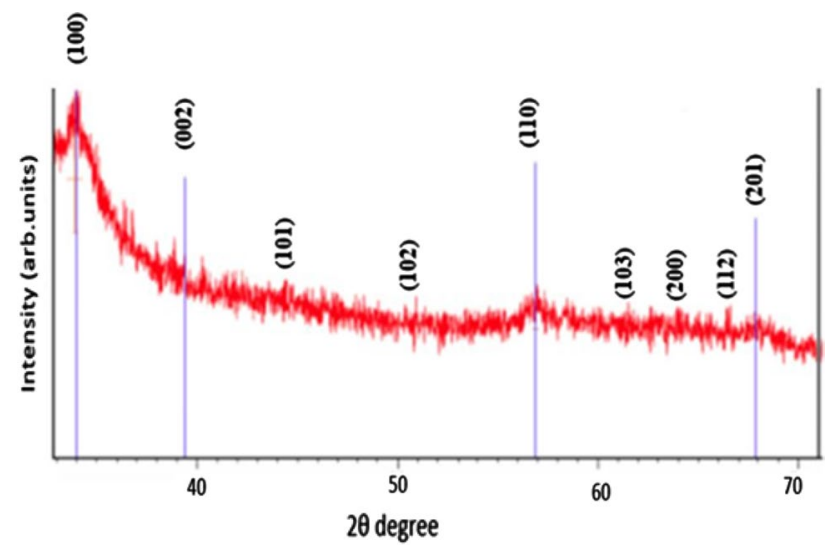

Fig. 9 XRD pattern of ZnO.NPs

standard card of bulk $\mathrm{ZnO}$ with hexagonal structure, there is no diffraction peaks of other impurities, which shows that the substances only belong to $\mathrm{ZnO}$, the average grain size of the particles was calculated for the peak (100) using the Debye scherrer formula and was estimated to be $14.7 \mathrm{~nm}$.

\subsection{Electrical properties}

The current-voltage characterization of thin films were carried out under illumination of solar Simulator with Kiethley source meter (2400 SMU). The short-circuit current $\left(\mathrm{I}_{\mathrm{SC}}\right)$ and opencircuit voltage $\left(\mathrm{V}_{\mathrm{OC}}\right)$ was recorded. Figure 10 shows the graph of ZnONPS current-voltage characteristics. Fill-factor (FF) and efficiency ( $\eta$ ) were calculated using Eqs. (5) and (6) respectively.

$F F=\frac{P \max }{1 s c V o c}=\frac{1 m p V m p}{1 s c V o C}$

$\eta=\frac{I_{S C} \cdot V_{O C} \cdot F F}{P_{i n}}$

The fabricated thin film device of ZnO.NPs under illumination has efficiency of $0.7 \%$. 
Fig. 10 Current-voltage characteristics for ZnO.NPs thin film device

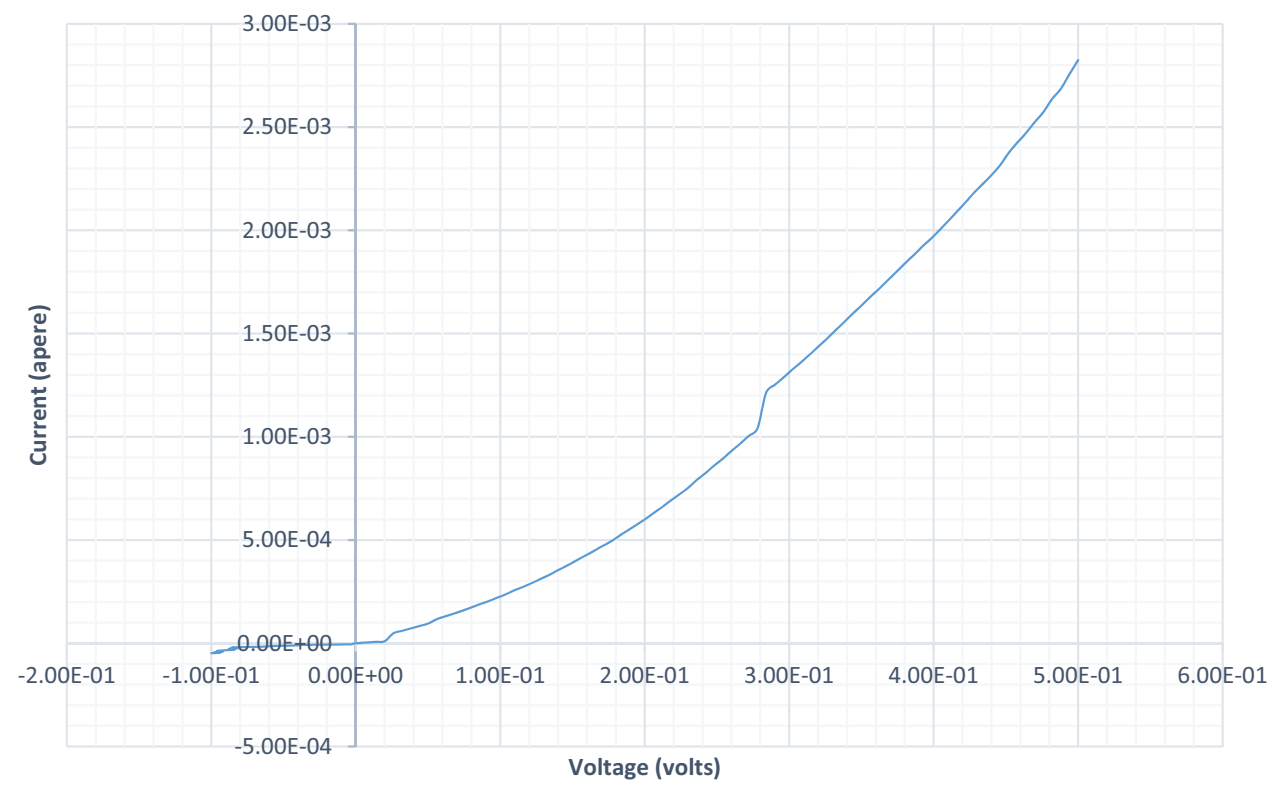

\section{Conclusion}

The research focus on synthesis, characterization of ZnO.NPs and evaluation of its properties. UV-VIS spectrum analysis shows ZnO.NPs thin film has a range of absorption that occurs from 235 to $300 \mathrm{~nm}$ and $350 \mathrm{~nm}$ upward in visible spectrum. The FTIR of synthesized ZnO NPs shows $\mathrm{Zn}-\mathrm{O}$ functional group was found at low wavenumber which agrees with results reported by $[7,11,15,32]$. The SEM images give information on the morphology of the sample, the structure of $\mathrm{ZnO}$ provides direct pathways for the electrons to move through the cell and thus increase the energy conversion rate. The XRD pattern of powder ZnO.NPs shows the peaks indexed to $\mathrm{ZnO}$ with the hexagonal wurtzite structure and the average grain size of the particles was estimated to be $14.7 \mathrm{~nm}$. The environmental consideration and the phytochemical present in the plant make it suitable for the synthesis procedure, because of not polluting and less hazardous to the community compared to the chemical method. Sustainable potential is inherent in the availability of the plant in abundance. ZnO.NPs thin film device under illumination has efficiency of $0.7 \%$. Based on the optical, structural and electrical properties of the fabricated thin film device, it was therefore recommended that the observed parameters could be suitable for photoanode in Dye sensitized solar cells for performance enhancement.

Acknowledgements The authors would wish to acknowledge Mr. Oyeshola Hakeem Olayinka for his contribution in XRD analysis and Materials Science and Engineering Department of Kwara State University Malete-Ilorin for providing research facilities and encouragements.

\section{Compliance with ethical standards}

Conflict of interest We declare that we have no conflict of interest.

\section{References}

1. Kumar SS, Venkateswarlu P, Rao VR (2013) Synthesis, characterization and optical properties of zinc oxide nanoparticles. Int Nano Lett 3:30

2. Eric MA (1998) Synthesis and growth of $\mathrm{ZnO}$ nanoparticles. J Phys Chem B 102:5566-5572

3. Prasad K, Jha AK (2009) ZnO nanoparticles: synthesis and adsorption study. Nat Sci 1(2):129-135

4. Sadraei R (2016) A simple method for preparation of nano-sized ZnO. Res Rev J Chem 5(2):45-49

5. Zhao L-H, Zhang R, Zhang J, Sun S-Q (2012) Synthesis and characterization of biocompatible $\mathrm{ZnO}$ nanoparticles. Cryst Eng Commun 14:945-950

6. Vasireddy R, Paul R, Mitra AK (2012) Green synthesis of silver nanoparticles and the study of optical properties. Nanomater Nanotechnol 2:8

7. Becheri A, Durr M, Nostro PL, Baglioni P (2008) Synthesis and characterization of Zinc Oxide nanoparticles: application to textiles as UV- absorbers. J Nanopart Res 10:679-689

8. Vaseem M, Umar A, Yoon-Bong H (2010) ZnO nanoparticles: growth, properties, and applications. Met Oxide Nanosruct Appl 5:1-36

9. Young M (2016) Synthesis of zinc oxide nanoparticles with different morphology by wet chemistry routes Doctoral Thesis submitted in partial fulfilment of the requirements for the award of doctor of philosophy of Loughborough University

10. Ramesh P, Rajendran A, Subramanian A (2014) Synthesis of zinc oxide nanoparticles from fruit of citrus aurantifolia by chemical and green method. Asian J Phytomed Clin Res 2(4):189-195

11. Dobrucka R, Dugaszewka J (2016) Bios ynthesis and antibacterial activity of $\mathrm{ZnO}$ nanoparticles using Trifolium pratense flower extract. Saudi J Biol Sci 23:517-523 
12. Geetha MS, Nagabhushang $H$, Shivananjaiah HN (2016) Green medicated synthesis and characterization of $\mathrm{ZnO}$ nanoparticles using Euphorbia Jatropa latex as reducing agent. J Sci Adv Mater Devices 1:301-310

13. Fatimah I, Praditaa RY, Nurfalindaa A (2016) Plant extract mediated of $\mathrm{ZnO}$ nanoparticles by using ethanol extract of Mimosa pudica leaves and coffee powder. In: 4th international conference on process engineering and advanced materials, procedia engineering, vol 148, pp 43-48

14. Matinise N, Fuku XG, Kaviyarasu K, Mayedwe N, Maaza M (2017) ZnO nanoparticles via Moringa Oleifera green synthesis: physical properties \& mechanism of formation. Appl Surf Sci 406:339-347

15. Taufiq A, Ulya HN, Utomo J, Sunaryono, Hidayat N, Susanto $H$, Mufti N, Munasir, Soontaranon S (2018) Structural, optical, and antifungal characters of zinc oxide nanoparticles prepared by sol-gel method. J Phys Conf Ser 1093:012001

16. Fakhari S, Jamzad M, Fard HK (2019) Green synthesis of zinc oxide nanoparticles: a comparison. Green Chem Lett Rev 12(1):19-24

17. Bahtiar A (2016) Charge carriers motion in P3HT: capped $\mathrm{ZnO}$ nanoparticles blend films; impact of capping agents. KnE Eng. https://doi.org/10.18502/keg.v1i1.495

18. Patidar D, Kaswan A, Saxena NS, Sharma K (2013) Monodispersed $\mathrm{ZnO}$ nanoparticles and their use in heterojunction solar cell. Sci World J 2013, ArticleID260521, 6 pages Article in The Scientific World Journal

19. Green MA (1982) Solar cells: operating principles, technology and system applications. Prentice-hall, Englewood Cliffs

20. Tauc J (1970) The optical properties of solids, ed. F. Abeles. North-Holland, Amsterdam

21. Kumar IK, Balachandraand PR (2011) Synthesis and characterization of nano zinc oxide by gel spin coating. Recent Res Sci Technol 3(3):4852

22. Gupta A, Srivastava P, Bahadur L, Amalnerkar DP, Chauhan R (2014) Comparison of physical and electrochemical properties of $\mathrm{ZnO}$ prepared via surfactant-assisted precipitation routes. Appl Nanosci 5:787-794
23. Preethi S, Anitha A, Arulmozhi M (2016) A comparative analysis of the properties of zinc oxide ( $\mathrm{ZnO}$ ) nanoparticles synthesized by hydrothermal and sol-gel methods. Indian J Sci Technol 9:1-6

24. Xiong G, Pal U, Serrano JG, Ucer KB, Williams RT (2006) Photoluminesence and FTIR study of $\mathrm{ZnO}$ nanoparticles: the impurity and defect perspective. Phys Status Solidi C 3:3577-3581

25. Hlaing Oo WM, McCluskey MD, Lalonde AD, Norton MG (2005) Infrared spectroscopy of ZnO nanoparticles containing CO [sub 2] impurities. Appl Phys Lett 86:073111

26. Kołodziejczak-Radzimska A, Markiewicz E, Jesionowski T (2012) Structural characterisation of $\mathrm{ZnO}$ particles obtained by the emulsion precipitation method. J Nanomater 2012:656353

27. Top A, Çetinkaya H (2015) Zinc oxide and zinc hydroxide formation via aqueous precipitation: effect of the preparation route and lysozyme addition Mater. Chem Phys 167:77-87

28. Hasanpour A, Niyaifar M, Asan M, Amighian J (2013) Synthesis and characterization of $\mathrm{Fe} 3 \mathrm{O} 4$ and $\mathrm{ZnO}$ nanocomposites by the sol-gel method. J Magn Magn Mater 334:41-44

29. Wahab R, Ansari SG, Kim YS, Seo HK, Kim GS, Khang G, Shin H-S (2007) Low temperature solution synthesis and characterization of ZnO nano-flowers. Mater Res Bull 42:1640-1648

30. Zandi S, Kameli P, Salamati H, Ahmadvand H, Hakimi M (2011) Microstructure and optical properties of $\mathrm{ZnO}$ nanoparticles prepared by a simple method Phys. B Condens Matter 406:3215-3218

31. Vafaee M, Ghamsari MS (2007) Preparation and characterization of $\mathrm{ZnO}$ nanoparticles by a novel sol-gel route. Mater Lett 61:3265-3268

32. Barreto GP, Morales G, Quintanilla ML (2013) Microwave assisted synthesis of $\mathrm{ZnOx}$, temperature, irradiation time, and additives on Nano-ZnO morphology development. J Mater 2013:1-11

Publisher's Note Springer Nature remains neutral with regard to jurisdictional claims in published maps and institutional affiliations. 